\title{
Desacuerdos entre patrimonio, paisaje y medio ambiente: a propósito de Punta Nati (Reserva de la Biosfera de la Unesco en Menorca)
}

\author{
Rocío Silva Pérez \\ Víctor Fernández Salinas \\ Universidad de Sevilla. Departamento de Geografía Humana \\ rsilva@us.es \\ salinas@us.es
}

\section{Resumen}

Este artículo versa sobre los desacuerdos generados por cambios de usos del suelo en espacios de elevado valor patrimonial derivados de actuaciones contradictorias en sus efectos ambientales, patrimoniales y paisajísticos. Se centra en la polémica suscitada por tres proyectos de energías renovables previstos en Punta Nati (zona noroccidental de Menorca). Se plantean dos objetivos: 1) analizar los cambios asociados a la evolución desde un paisaje predominantemente ganadero a otro mixto ganadero y energético, atendiendo a los valores patrimoniales que se comprometen y al soporte normativo sobre los que se sustentan, y 2) identificar a los actores protagonistas de la polémica y sus percepciones y actitudes ante los cambios. El ejemplo de Punta Nati es significativo y expresivo del debate patrimonial y ambiental actual y se centra en las potencialidades del paisaje para dirimir problemas territoriales complejos.

Palabras clave: patrimonio; paisaje; medio ambiente; reservas de la biosfera de la Unesco; Punta Nati (Menorca) 
Resum. Desacords entre patrimoni, paisatge i medi ambient: a propòsit de Punta Nati (Reserva de la Biosfera de la Unesco a Menorca)

Aquest article tracta sobre les desavinences generades per canvis en l'ús del sòl en zones de valor patrimonial alt derivats de les actuacions contradictòries en els seus efectes ambientals, patrimonials i paisatgístics. Se centra en la polèmica plantejada per tres projectes d'energies renovables previstes a Punta Nati (nord-oest de Menorca). Hi ha dos objectius: 1) analitzar els canvis associats a l'evolució d'un paisatge predominantment ramader a un altre mixt ramader i energètic, segons els valors de patrimoni que s'hi han compromès i el suport normatiu en el qual es basen, i (2) identificar els protagonistes de la polèmica i les seves percepcions i actituds respecte als canvis. L'exemple de Punta Nati és significatiu i expressiu del debat patrimonial i ambiental actual i se centra en el potencial del paisatge per resoldre problemes territorials complexos.

Paraules clau: patrimoni; paisatge; medi ambient; reserves de la biosfera de la Unesco; Punta Nati (Menorca)

Resumé. Désaccords entre patrimoine, paysage et environnement : À propos de Punta Nati (Réserve de biosphère de l'Unesco à Minorque)

Cet article traite des désaccords générés par les changements dans l'utilisation des terres dans des espaces de haute valeur patrimoniale dérivés d'actions contradictoires dans leurs effets environnementaux, patrimoniaux et paysagers. Il se centre sur la controverse soulevée par trois projets d'énergies renouvelables prévus à Punta Nati (région Nord-Ouest de Minorque). L'article se donne deux objectifs : 1) analyser les changements associés à l'évolution d'un paysage avec une prédominance du bétail à un autre mélangeant bétail et énergie en tenant compte des valeurs patrimoniales qui sont engagées et du soutien normatif sur lequel ils sont soutenus, et 2) d'identifier les protagonistes de la controverse ainsi que leurs perceptions et attitudes face aux changements. L'exemple de Punta Nati est significatif et représentatif du débat patrimonial et environnemental actuel ; il met l'accent sur le potentiel du paysage à résoudre des problèmes territoriaux complexes.

Mots-clés: patrimoine; paysage; environnement; réserves de la biosphère de l'Unesco; Punta Nati (Minorque)

Abstract. Disagreements between heritage, landscape and environment: The Punta Nati UNESCO Biosphere Reserve in Menorca

This paper examines disagreements arising from land use changes in areas of high heritage value due to contradictory actions with environmental, heritage and landscape effects. The article focuses on the controversy over three renewable energy projects planned in the Punta Nati Biosphere Reserve of northwest Menorca. The objectives are 1) to analyze the changes associated with the evolution from a predominantly livestock landscape to a mixed livestock and energy-based landscape, taking into account heritage values and the normative support on which they are sustained; and 2) to identify the main agents of the dispute and their perceptions and attitudes toward the changes. The Punta Nati case is a good example of the current heritage and environmental debate and the potential of the concept of landscape to resolve complex territorial problems.

Keywords: heritage; landscape; environment; Unesco biosphere reserves; Punta Nati; Menorca 


\section{Sumario}

1. Presupuestos de la investigación

2. Marco empírico de la investigación: caracterización territorial y normativa de Punta Nati
3. Proyectos de energías renovables previstos en el paraje de Punta Nati y sus valoraciones sociales

4. Conclusiones

Referencias bibliográficas

\section{Presupuestos de la investigación}

Los cambios de uso del suelo en espacios de elevado valor patrimonial se perciben habitualmente como negativos y suelen ser objeto de controversia y contestación. Abundan los estudios sobre las pérdidas de los valores culturales por la regresión de la agricultura tradicional (Castillo Ruiz y Martínez Yáñez, 2014; Silva Pérez, 2008); el avance de la urbanización (Delgado Viñas, 2008; Ainz Ibarrondo y González Amuchástegui, 2016; la progresión de los usos turísticos (Conti y Gravero Igarza, 2010; González et al., 2016), etcétera. El debate se matiza cuando las modificaciones tienen que ver con la instalación de plantas de energías renovables, ya que generan percepciones encontradas en sus efectos ambientales, patrimoniales y paisajísticos.

Entre las causas de esos matices y controversias está el mayor calado social e institucional del discurso ambiental y energético respecto al debate patrimonial y paisajístico. Las secuelas de la industrialización y la modernización de los sistemas productivos (desaparición de especies y espacios emblemáticos; contaminación y alteración de hábitats; agotamiento de recursos; etcétera) avivó la cuestión ambiental en los años ochenta, especialmente a partir del informe Bruntland en 1987. La generalización de las políticas y la aparición de las primeras redes de espacios naturales protegidos expresa esa preocupación (Batisse, 1982). Las sucesivas crisis energéticas y, más recientemente, la inquietud por el cambio climático han situado las energías limpias en las agendas políticas y en el debate ciudadano (Devine-Wright y Devine-Wright, 2006; Frolova et al., 2014). El discurso patrimonial y paisajístico, también intenso en estos años (Silva et al., 2018) se ha movido, en cambio, más en los ámbitos académico y legislativo habiendo alcanzado menos a la opinión pública. La asimilación entre energías limpias y calidad ambiental pesa más en los idearios sociales e institucionales que los valores patrimoniales y paisajísticos de los territorios. En estrecha relación con ello está la menor atención dispensada a la actividad energética como generadora de paisajes (Herrero y Baraja, 2017).

Esto último parece estar cambiando en los últimos años. Los estudios sobre los impactos paisajísticos de las instalaciones energéticas (Andrés e Iranzo, 2011; Díaz et al., 2016; Frolova et al., 2014), los conflictos que suscitan (Briffaud et al., 2015; Cowell, 2010) y las percepciones y las valoraciones sociales que merecen (Devine-Wright y Devine-Wright, 2006; Frolova, 2010; West et al., 2010) así lo atestiguan. Este trabajo se inserta en esa línea y se centra 
en la polémica suscitada por tres proyectos de energías renovables previstos en Punta Nati (Menorca), con un impacto que compromete la riqueza patrimonial y escénica de paisajes ganaderos ancestrales y con referentes arqueológicos relacionados con la cultura talayótica (2100 a. C.). Desde 1993 la totalidad de Menorca se integra en la Red de Reservas de la Biosfera del programa MaB (Man and Biosphere) de la Unesco; a su vez, Menorca Talayótica es una candidatura a la Lista del Patrimonio Mundial de la misma organización, reconducida en los últimos meses hacia la tipología de paisaje cultural. La polémica reproduce la dicotomía existente en el patrimonio (natural frente a cultural), superada en el ámbito conceptual y en los convenios internacionales, pero todavía vigente en las percepciones sociales y en la gestión pública.

En términos conceptuales el trabajo maneja tres nociones polisémicas, complejas y entrelazadas: medio ambiente, patrimonio y paisaje. Se parte de la hipótesis de que las tres difieren según el tipo de bienes prioritariamente atendidos: genéricos —ubicuos - o específicos — anclados en territorios concretos- (Méndez, 2002). Los recursos naturales ligados a la calidad ambiental (el agua, el aire, el viento, etcétera, así como su utilización a través de energías limpias) se inscriben entre los primeros. Su preservación no entiende de fronteras y la responsabilidad de su gestión no debería hacerse recaer en unidades territoriales concretas, por más que estas desempeñen un papel clave en la gestión sostenible de esos recursos. Los bienes patrimoniales (naturales, culturales o paisajísticos) son, en cambio, recursos específicos enraizados en los territorios y precisan, en consecuencia, de una gestión territorializada. Como hipótesis secundaria se mantiene que los instrumentos normativos vigentes son inoperantes para la preservación de los valores patrimoniales de paisajes culturales de dominante agraria.

\subsection{Objetivos, metodología y fuentes}

El trabajo plantea dos objetivos básicos: 1) analizar los cambios asociados a la evolución desde un paisaje predominantemente ganadero hasta otro mixto ganadero y energético en Punta Nati, atendiendo a los valores patrimoniales que se comprometen con estos cambios y al soporte normativo sobre los que estos se sustentan, y 2) identificar a los actores protagonistas de la polémica y sus percepciones y actitudes ante los cambios. Subsidiariamente también se persigue adentrarse en el debate sobre el territorio como bien patrimonial a través del paisaje.

La metodología empleada parte de la definición de las bases epistemológicas y normativas en la literatura especializada y del análisis de referentes documentales relacionados con la protección, la ordenación y la gestión de los recursos patrimoniales con que cuentan los territorios, por una parte, y con el concepto de medio ambiente y su vinculación a la utilización racional de los recursos y al uso de energías renovables, por otra. En un segundo momento se acomete la fase empírica consistente en: 1) la caracterización territorial del ámbito seleccionado y la determinación de sus valores patrimoniales; 2) la localización de 
los proyectos de energías renovables atendiendo a sus impactos patrimoniales y paisajísticos, y 3) la identificación de los agentes implicados y la indagación de sus percepciones y valoraciones respecto al cambio de usos.

Se ha recurrido a las siguientes fuentes:

- Referencias bibliográficas y documentales relacionadas al final del trabajo.

- Entrevistas a los principales agentes institucionales y sociales concernidos: responsables de distintos departamentos del Consell Insular de Menorca (Servicio de Ordenación del Territorio y Turismo; departamentos de Medio Ambiente y Reserva de la Biosfera y de Cultura y Educación); asociación ecologista GOB Menorca y Societat Arqueològica Martí i Bella. Las entrevistas datan de enero de 2017.

- Mesas de debate participadas por los agentes antes reseñados y por expertos y representantes de la sociedad civil realizadas en el marco de las I Jornadas de Trabajo del Grupo de Paisaje de la Asociación de Geógrafos Españoles celebradas en Maó los días 15 y 16 de junio de 2017).

- Trabajo de reconocimiento territorial en el paraje de Punta Nati (realizado en enero y junio de 2017).

\subsection{Paisaje, patrimonio y medio ambiente: Bases epistemológicas y normativas}

Paisaje, patrimonio y medio ambiente son conceptos polisémicos y entrelazados. Sus bases epistemológicas, originariamente dispares, han convergido en atribuciones e intencionalidades, pero en términos institucionales y normativos cada uno de ellos continúa recibiendo un tratamiento diferenciado (tabla 1). Ello los convierte en conceptos de difícil lectura que, por una parte, se identifican y se confunden, $y$, por otra, dan lugar a desencuentros perceptivos y a conflictos territoriales.

El concepto de paisaje es académico y en el mundo occidental está relacionado con la estética y las panorámicas de los territorios (en disciplinas como las bellas artes, la arquitectura, etcétera), y con las relaciones entre el hombre y el medio y sus configuraciones morfológicas (en geografía y ecología del paisaje, entre otras). El Convenio Europeo del Paisaje (Consejo de Europa, 2000) conceptúa el paisaje y lo convierte en objeto transversal entre disciplinas. Se refiere al paisaje como percepción ("paisaje es cualquier parte del territorio tal como lo percibe la población", artículo 1) y hace recaer esta noción en todos los paisajes con independencia de la dominante de su carácter (rural, urbana, periurbana, agraria, industrial, energética, etcétera) o de su condición excelsa, cotidiana e incluso degradada (artículo 2). Insta, en consonancia con lo anterior y según los casos, a la protección de los valores patrimoniales, a la gestión de los cambios y a la ordenación y proyección paisajísticas. En términos operativos la mayor parte de esos cometidos se hace recaer en la ordenación del territorio, sin menoscabo de otras políticas sectoriales (infraestructuras, agrarias, etcétera). El convenio supone el reconocimiento de la agricultura como paisaje y considera la capacidad de creación de nuevos paisajes, entre ellos los energéticos. 
Tabla 1. Paisaje, patrimonio y medio ambiente: Conceptos, atribuciones, intenciones y normas

\begin{tabular}{|c|c|c|c|c|}
\hline \multirow{2}{*}{\multicolumn{2}{|c|}{ Conceptos Atribuciones }} & \multirow[b]{2}{*}{ Intenciones } & \multicolumn{2}{|c|}{ Normas y convenios } \\
\hline & & & Genéricas & $\begin{array}{l}\text { Específicas } \\
\text { internacionales }\end{array}$ \\
\hline Paisaje & $\begin{array}{l}\text { Estéticas. } \\
\text { Panorámicas. } \\
\text { Todo el territorio. }\end{array}$ & $\begin{array}{l}\text { Protección. } \\
\text { Ordenación y } \\
\text { creación de paisajes. } \\
\text { Gestión. }\end{array}$ & $\begin{array}{l}\text { Planificación urba- } \\
\text { nística y territorial. } \\
\text { Políticas sectoriales } \\
\text { de incidencia espa- } \\
\text { cial (infraestructuras, } \\
\text { agrarias, etcétera). }\end{array}$ & $\begin{array}{l}\text { Convenio Europeo } \\
\text { del Paisaje (Consejo } \\
\text { de Europa, 2000). }\end{array}$ \\
\hline $\begin{array}{l}\text { Patrimonio } \\
\text { natural }\end{array}$ & $\begin{array}{l}\text { Especies. } \\
\text { Espacios. }\end{array}$ & Preservación. & $\begin{array}{l}\text { Normas reguladoras } \\
\text { del patrimonio natu- } \\
\text { ral / Instituciones } \\
\text { ambientales. }\end{array}$ & $\begin{array}{l}\text { Convención del } \\
\text { Patrimonio Mundial, } \\
\text { Cultural y Natural } \\
\text { (Unesco, 1972). }\end{array}$ \\
\hline $\begin{array}{l}\text { Patrimonio } \\
\text { cultural }\end{array}$ & $\begin{array}{l}\text { Bienes inmuebles } \\
\text { (monumentos, con- } \\
\text { juntos históricos, } \\
\text { etcétera). } \\
\text { Bienes inmateriales. }\end{array}$ & Preservación. & $\begin{array}{l}\text { Normas reguladoras } \\
\text { del patrimonio cultu- } \\
\text { ral / Instituciones del } \\
\text { patrimonio cultural. }\end{array}$ & $\begin{array}{l}\text { (Unesco, 1971). } \\
\text { Programa Interna- } \\
\text { cional de Geocien- } \\
\text { cias y Geoparques } \\
\text { (Unesco, 2015). }\end{array}$ \\
\hline & Paisajes culturales. & & & Directiva 79/09/ \\
\hline $\begin{array}{l}\text { Medio } \\
\text { ambiente }\end{array}$ & $\begin{array}{l}\text { Aire, suelo, agua. } \\
\text { Especies naturales } \\
\text { y vegetales. } \\
\text { Naturaleza o medio } \\
\text { natural. }\end{array}$ & $\begin{array}{l}\text { Preservación } \\
\text { de espacios. } \\
\text { Gestión de recursos. }\end{array}$ & $\begin{array}{l}\text { Normas reguladoras } \\
\text { del patrimonio natu- } \\
\text { ral / Instituciones } \\
\text { ambientales. } \\
\text { Normas sectoriales. }\end{array}$ & $\begin{array}{l}\text { to Europeo y del } \\
\text { Consejo relativa a } \\
\text { la Conservación de } \\
\text { las Aves Silvestres } \\
\text { (reemplazada por la } \\
\text { Directiva 2009/147/ } \\
\text { CE). }\end{array}$ \\
\hline
\end{tabular}

Fuente: elaboración propia.

La noción de patrimonio es originariamente normativa. Sus primeros postulados se contienen en leyes decretadas por los estados modernos tendentes a la preservación de: $a$ ) espacios vírgenes y poco intervenidos por el género humano (parques nacionales, como el de Yellowstone), y b) monumentos y ámbitos que habían dejado de estar habitados y de ser aprovechados funcionalmente: los yacimientos arqueológicos. El patrimonio se identificaba originariamente, pues, con elementos puntuales o acotados (monumentos y zonas arqueológicas) y con espacios excelsos o muy singulares merecedores de conservación. En este contexto, los espacios híbridos de naturaleza y cultura, como los paisajes agrícolas y ganaderos, no tenían cabida.

Con posterioridad, esta noción de patrimonio ha perdido esa condición de excelsitud, ha integrado patrimonios modestos (la obra pública, la arquitectura vernácula, los bienes etnográficos) y se ha acercado al territorio a través de la valoración de los paisajes cotidianos y funcionales. La figura de paisaje cultural incorporada a la Convención del Patrimonio Mundial Natural y Cultural de la Unesco en 1992 a través de las directrices prácticas para su aplicación es un 
ejemplo de esto último. Para lo que aquí interesa no es baladí, puesto que se trata de una figura en buena parte pensada para el reconocimiento patrimonial de paisajes agrarios.

Otros procesos confluyentes en la consideración de territorio como bien patrimonial son los siguientes:

— La asimilación, mezcla y fusión (también confusión) entre patrimonio natural y cultural, asumida al menos sobre el papel por varios convenios internacionales de la propia Unesco (Convención para la Protección del Patrimonio Mundial Cultural y Natural — 1972_; Programa MaB y su red de Reservas de la Biosfera - 1971—, y Programa de Geoparques Globales - 2015-); pero no siempre a efectos prácticos, en los que las visiones tradicionales se imponen. Esto último trasciende a las normas estatales (y autonómicas en el caso español), responsables directas de la gestión de los territorios, que persisten en la separación entre naturaleza y cultura.

- Lo anterior no es óbice para que el patrimonio natural se haya humanizado y el cultural se haya naturalizado. La figura de parque natural protagonista hoy de las redes de espacios naturales protegidos nacionales y autonómicas ilustra esa paradójica andadura (Mulero, 2017).

- El patrimonio se entiende hoy como construcción social y asignación de valores. Ello implica que todo patrimonio está mediatizado por la cultura y es patrimonio cultural independientemente del tipo de bienes (naturales o culturales) sobre los que recaiga ese valor, y también comporta el entendimiento del patrimonio como un doble proceso de reconocimiento y apropiación en dos direcciones: de arriba abajo, cuando son las instituciones las inductoras de la patrimonialización, y de abajo arriba, cuando el protagonismo recae en la sociedad civil (Prats, 2005; Silva Pérez y Fernández Salinas, 2017).

La tercera noción manejada en este trabajo, medio ambiente, es así mismo compleja. Sus atribuciones se proyectan sobre vectores intangibles (o menos tangibles que el paisaje y los bienes patrimoniales convencionales), tales como el aire, el agua o el suelo, y también se relacionan con el estado de la vegetación y de la fauna. Esta última acepción ha determinado que, en su percepción más común, se identifique ambiente con naturaleza y se equipare medio ambiente a medio natural. El resultado es la asimilación (y la confusión) entre medio y recursos naturales. La gestión del primero compete a las instituciones ambientales y de conservación de la naturaleza, centrada en el reconocimiento (como parques nacionales, parques naturales, paisajes protegidos, etcétera) de los valores idiosincrásicos de cada espacio natural protegido. Los recursos naturales como el aire, el agua, el suelo o el medio ambiente en general no se circunscriben, en cambio, a ámbitos concretos. Su uso sostenible compete a las administraciones sectoriales. Esta diferenciación se obvia a menudo, de modo que la equiparación entre paisaje pretendidamente natural y medio ambiente relativamente saludable está muy extendida (Folch y Bru, 2017). 


\section{Marco empírico de la investigación: caracterización territorial y normativa de Punta Nati}

El paraje de Punta Nati es uno de los más conspicuos del archipiélago balear. Se da la circunstancia de que se inserta, además, en una isla integrada en la Red de Reservas de la Biosfera de la Unesco. Sin embargo, y a pesar de sus valores, estos son reconocidos, cuando lo son, de forma indirecta, y no por su importancia intrínseca dentro del campo patrimonial, tanto natural como cultural.

\subsection{Punta Nati, un paisaje singular en la Reserva de la Biosfera de Menorca}

Punta Nati es un paraje de 2.950 hectáreas situado en la Tramuntana de Ciutadella (extremo noroccidental de Menorca; figura 1). Morfológicamente su paisaje es un amplio valle en artesa cuya zona central bascula hacia un acantilado sobre el mar. Cromáticamente destaca por la alternancia de colores terrosos y blanquecinos en el contexto de una isla verde, con la que comparte una estructura de microparcelas que semejan las teselas de un mosaico asociadas a los usos agrarios del suelo.

La singularidad de Punta Nati en el contexto menorquín deviene de su combinación de componentes naturales y antrópicos. Su soporte estructural son calizas miocenas que dan lugar a suelos poco profundos o inexistentes. La pobreza edáfica, junto con la incidencia del viento de la tramuntana, determinan un uso ganadero ancestral como tercer elemento básico y definitorio de estos paisajes. Las especies y razas ganaderas tradicionales, hoy en peligro de extinción, están enraizadas con la historia económica y el patrimonio cultural de estos predios a través de la vaca menorquina, de excepcional aptitud quese-

Figura 1. Localización de Punta Nati

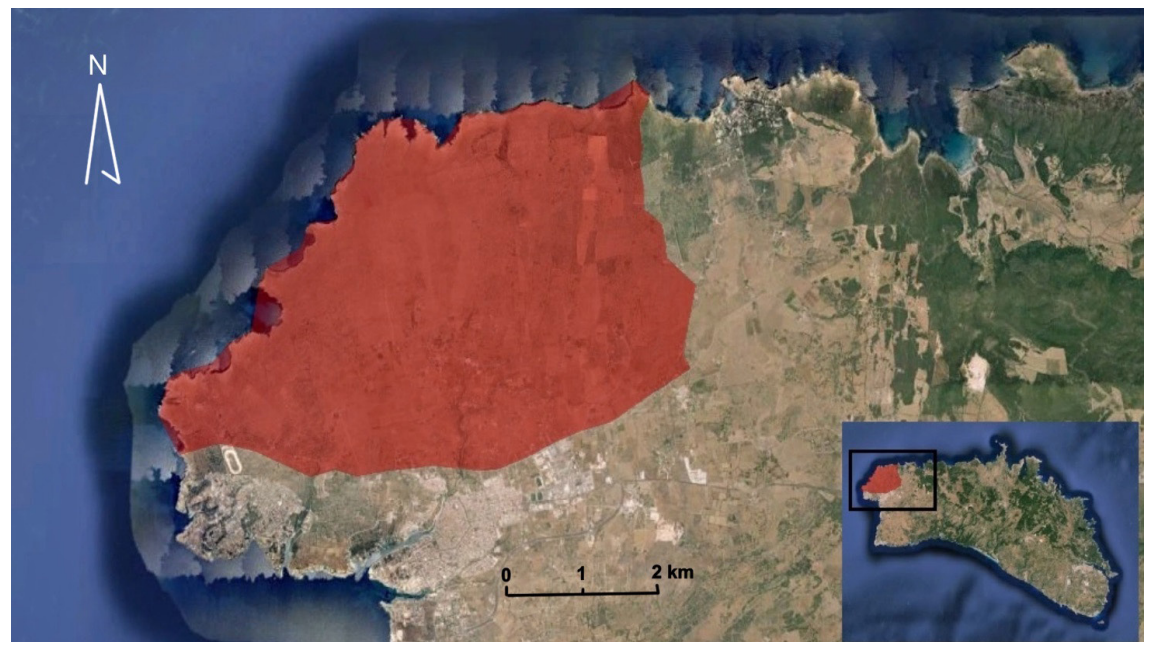

Fuente: Societat Arqueològica Martí i Bella (2013: 1). 
Figura 2. Muros de piedra en Punta Nati

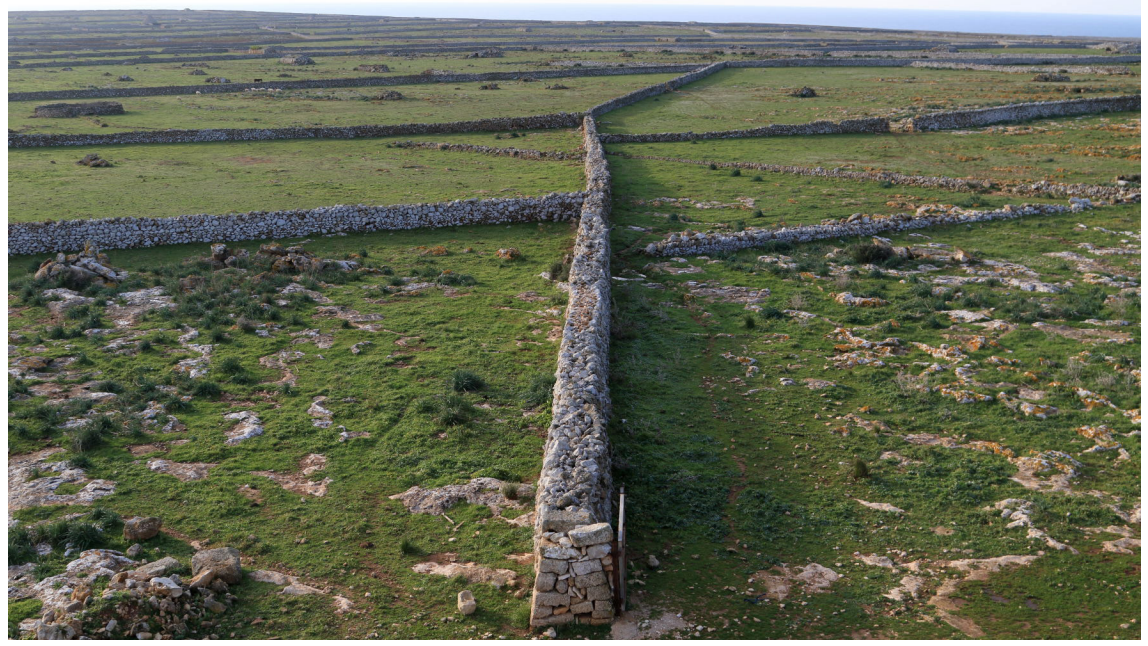

Fuente: fotografía de los autores (20/1/2017).

ra, que convivía con el ganado ovino en las cercas de piedras (tanques). De la oveja menorquina quedan pocos ejemplares y la vaca autóctona prácticamente ha desaparecido tras haber sido sustituida en la industria quesera actual por la frisona, de procedencia holandesa y explotada en cebaderos.

Como el resto de la isla, la construcción histórica del territorio de Punta Nati se remonta al calcolítico (2100 a. C.). Está representada por la cultura talayótica, pero sus trazas fisonómicas más visibles se concretan en la Baja Edad Media en forma de paisaje ganadero compartimentado por muros de piedra seca (figura 2) y salpicado de edificaciones circulares (barraques, figura 3) o cuadrangulares (ponts), todos ellos de rasgos constructivos emparentados con los talaiots. También es particular la red caminera que une las parcelas, en tanto que poseen servidumbres de paso complejas y que se concretan en muescas y escalones en los muros de piedra que las separan para facilitar el paso humano e impedir el del ganado. Durante el siglo XviII se acrecientan los usos ganaderos (y con ello la pobreza edáfica), al tiempo que la ocupación británica conlleva la decadencia de estos predios señoriales y eclesiásticos, capitalizados por Ciutadella en el oeste de la isla, frente a la emergencia de la comercial Maó en la parte oriental. Se inicia así un declive continuado que enlaza con la crisis de la agricultura tradicional (años setenta del siglo pasado) y su corolario de abandonos, deterioros y olvidos. Su culmen es la minusvaloración patrimonial de este paisaje y la aparición de nuevos usos suburbanos y energéticos poco coherentes con sus invariantes básicas. 


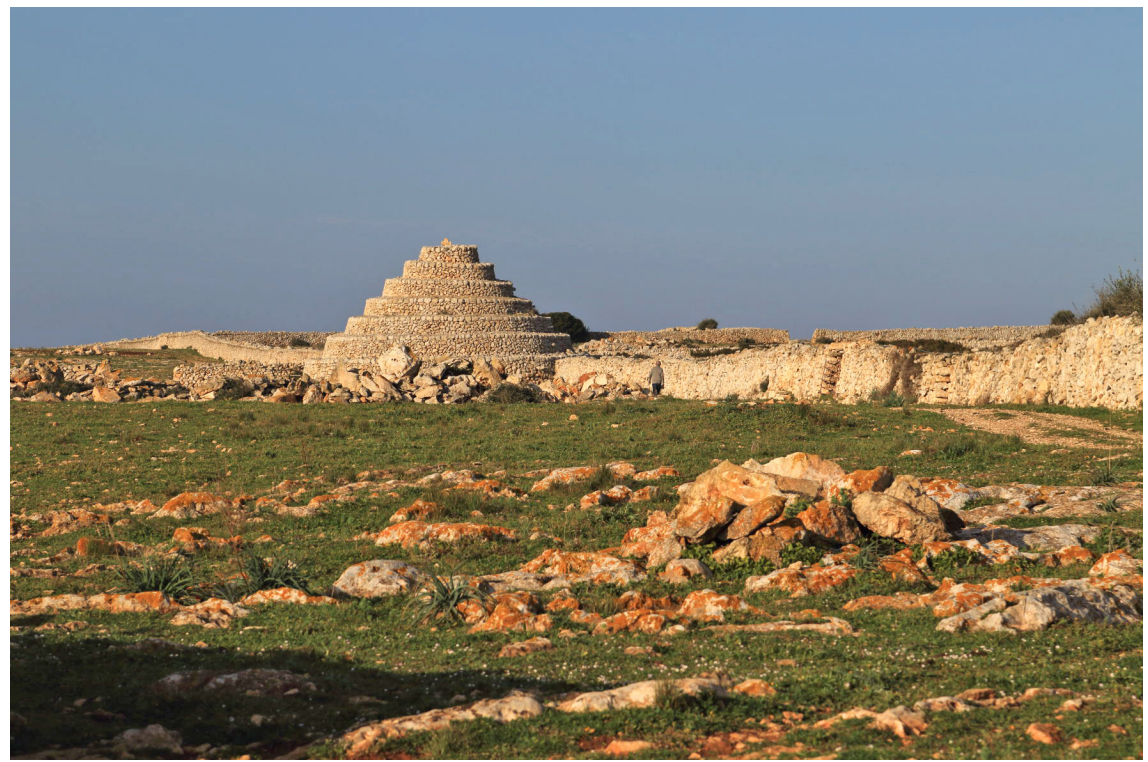

Fuente: fotografía de los autores (20/1/2017).

\subsection{Punta Nati, un paisaje sin protección territorial especifica}

El paraje de Punta Nati cuenta con recursos naturales, culturales y escénicos de gran valor: vistas panorámicas desde los acantilados; bufadors; aves en peligro de extinción (alimoches, pardela balear, águila pescadora); talaiots (Torre Vella d'en Lozano); rutas defensivas de avistamiento y control de la costa (Camí de Cavalls); faro construido en 1914 para orientar la navegación en el peligroso litoral noroeste de la isla; paisajes ganaderos ancestrales con elementos constructivos de gran valor (los citados tanques, barraques y ponts) y un patrimonio genético considerable en forma de razas en peligro de extinción (ovejas y vacas menorquinas); etcétera. Algunos de estos recursos se integran en enclaves con reconocimientos institucionales del más alto nivel. Tales reconocimientos no afectan, no obstante, a todo el paraje de Punta Nati y no incluyen el paisaje ganadero (tabla 2).

Desde 1993 toda Menorca forma parte de la Red de Reservas de la Biosfera de la Unesco. Se trata de un total de 70.200 hectáreas (incluyendo un área marítima), de las que el 4\% forma la zona núcleo; el 39\%, la zona de amortiguamiento (buffer zone en la terminología de la Unesco), y el 57\%, la zona de transición. Ningún paraje de Punta Nati integra la zona núcleo; su franja litoral, coincidiendo con la que está protegida por los convenios europeos, se integra en la zona de amortiguamiento y el resto se situaría en la llamada zona de transición. El paisaje ganadero afectado por los cambios de uso se incluye, 
Tabla 2. Recursos patrimoniales de Punta Nati según zonas y reconocimientos internacionales

\begin{tabular}{|c|c|c|c|}
\hline \multirow{2}{*}{$\begin{array}{l}\text { Recursos } \\
\text { - Acantilados y vistas } \\
\text { panorámicas. }\end{array}$} & \multirow{2}{*}{$\begin{array}{l}\text { Zonas } \\
\text { Franja litoral. }\end{array}$} & \multicolumn{2}{|c|}{ Reconocimientos internacionales } \\
\hline & & \multirow{5}{*}{$\begin{array}{l}\text { Lugar de Interés Comu- } \\
\text { nitario; Zona Especial de } \\
\text { Protección de Aves y Red } \\
\text { Natura } 2000 .\end{array}$} & $\begin{array}{l}\text { Reserva de la Biosfera Isla } \\
\text { de Menorca (1993). }\end{array}$ \\
\hline - Bufadors. & & & Menorca Talayótica \\
\hline - Camí de Cavalls. & & & (candidatura a la Lista del \\
\hline - Faro. & & & $\begin{array}{l}\text { Uatrımonio IVIundial) de la } \\
\text { Unesco en fase de prepa- }\end{array}$ \\
\hline $\begin{array}{l}\text { - Yacimientos arqueoló- } \\
\text { gicos. }\end{array}$ & $\begin{array}{l}\text { Resto del } \\
\text { territorio. }\end{array}$ & & ración. \\
\hline \multirow{3}{*}{\multicolumn{4}{|c|}{$\begin{array}{l}\text { - Poblado talayótico } \\
\text { Torre Vella d'en } \\
\text { Lozano. }\end{array}$}} \\
\hline & & & \\
\hline & & & \\
\hline \multicolumn{4}{|l|}{ - Paisaje ganadero. } \\
\hline $\begin{array}{l}\text { - Razas autóctonas en } \\
\text { peligro de extinción. }\end{array}$ & & & \\
\hline
\end{tabular}

Fuente: elaboración propia.

en suma, en la zona de menor celo en la protección de la reserva de la biosfera. Ello a pesar de que el texto de la declaración reconoce como un valor básico de Menorca, "[...] el alto grado de compatibilidad conseguido entre el desarrollo de las actividades económicas, el consumo de recursos y la conservación de un patrimonio y un paisaje que ha mantenido, y sigue manteniendo hoy, una calidad excepcional» (Declaración de Reserva de la Biosfera de 1993 citada en Menorca Reserva de Biosfera, en línea). La importancia concedida al género humano y a sus actividades tradicionales por parte del Programa MaB en las reservas de la biosfera parece quedar solo sobre el papel en el caso de Menorca.

Otra de las propuestas de reconocimiento internacional del patrimonio de la isla, que se encuentra en fase de preparación, es Menorca Talayótica, una candidatura a la Lista del Patrimonio Mundial de la Unesco reconducida hacia la figura de paisaje cultural. Los vestigios de esta cultura en Punta Nati no han sido incluidos en la candidatura a pesar de la envergadura de algunos de sus testimonios talayóticos (como los de Torre Vella d'en Lozano) y de las remembranzas constructivas con aquellos de las barraques y ponts ganaderos.

Otros distintivos internacionales como Lugar de Interés Comunitario y Zona de Especial Protección para las Aves afectan a la franja litoral de Punta Nati y, en razón de ello, se integran en la Red Natura 2000.

Los reconocimientos institucionales internacionales, en suma, prestan una atención muy marginal a Punta Nati, que siempre se encuentra limitada a sus parajes litorales. El paisaje ganadero no ha sido considerado hasta ahora en los expedientes de las declaraciones internacionales (tabla 2).

Las normas autonómicas con implicaciones directas en la gestión de los bienes patrimoniales de Menorca reproducen los sesgos antedichos. Su afección territorial es igualmente muy limitada (tabla 3), por lo que resultan insuficien- 
tes para la defensa de los parajes ganaderos de Punta Nati frente a proyectos de cambio de uso. Estas normas son:

- La Ley 1/1991, de Espacios Naturales y Régimen Urbanístico de las Áreas de Especial Protección de las Islas Baleares, reconoce la franja litoral de Punta Nati como Area Natural de Interés Territorial. Ello le confiere la máxima protección, en consonancia con su doble condición de Lugar de Interés Comunitario (LIC) y Zona de Especial Protección para las Aves (ZEPA) y su consiguiente integración en la Red Natura 2000.

- La Ley 12/1998, del Patrimonio Histórico de las Islas Baleares, (parcialmente modificada por la Ley 1/2005) cataloga en Punta Nati hasta ochenta bienes arqueológicos de interés cultural, todos ellos con una afección espacial muy puntual, lo que no preserva a este paraje frente a cambios de uso.

- El único bien cultural de Punta Nati con una protección patrimonial específica es el Camí de Cavalls, regulado por ley del Gobierno balear $(13 / 2000)$, que igualmente se sitúa en la franja litoral.

- El Plan Territorial Insular (aprobado en 2003, renovado en 2006, sustituido en 2014 por la Norma Territorial Transitoria y actualmente en proceso de revisión) reconoce el valor patrimonial de los paisajes de Punta Nati a través de dos figuras: a) Suelo Rústico protegido de especial interés coincidente con las Áreas Naturales de Interés Territorial de la Ley 1/1991 y circunscrito al área litoral; y b) Área de Interés Paisajistico, que se corresponde con buena parte del suelo rústico de uso ganadero. Ambas figuras recaen dentro de la llamada zona de transición de la reserva de la biosfera. Respecto a los cambios de uso, el Plan Territorial Insular de 2003 señala el «apoyo a la producción de energías alternativas (eólica, solar) a pequeña escala y limitación de grandes implantaciones, especialmente en las Áreas Naturales de Especial Interés y en las de Interés Paisajístico» (art. 62.4). No excluye, en consecuencia, las instalaciones energéticas entre los posibles cambios de uso, pero sí restringe sus tamaños.

— La modificación del Plan Territorial Insular de 2006 introdujo un cambio significativo decretando que «[...] se facilitarán y, en su caso, fomentarán las instalaciones eólicas o fotovoltaicas y fototérmicas, y también otras energías renovables, dirigidas al autoconsumo o a su comercialización, en todos los lugares (excepto en las áreas de alto nivel de protección) y en todo tipo de actividad, especialmente en el sector público, como ejemplo para promover el cambio energético y agrario» (Modificación del Plan Territorial de Menorca, art. 14). Ello supone de facto la prohibición de estas instalaciones en suelo rústico protegido de especial interés y su relegación a las áreas de interés paisajístico, que es la categoría asignada a los parajes ganaderos de Punta Nati.

- En 2014 se aprueba la Norma Territorial Transitoria, un instrumento más permisivo respecto a los cambios de uso urbanísticos y energéticos que los anteriores, y que a su vez ha sido derogada en 2017 y modificada por un nuevo plan territorial cuyo avance se aprobó en febrero de 2018. 
Tabla 3. Normas con incidencia en el paraje de Punta Nati y afecciones territoriales del Plan Territorial Insular

\begin{tabular}{|c|c|c|}
\hline Normas & Elementos y espacios catalogados & Afección territorial \\
\hline $\begin{array}{l}\text { Ley } 12 / 1998 \text {, de Patrimonio } \\
\text { Histórico de las Islas Baleares. }\end{array}$ & $\begin{array}{l}\text { Ochenta bienes de interés cultural } \\
\text { de carácter arqueológico. }\end{array}$ & Muy puntual. \\
\hline $\begin{array}{l}\text { Ley } 1 / 1991, \text { de Espacios Naturales } \\
\text { y Régimen Urbanístico de las Áreas } \\
\text { de Especial Protección de las Islas } \\
\text { Baleares. }\end{array}$ & Área natural de especial interés. & Franja litoral. \\
\hline $\begin{array}{l}\text { Plan Territorial Insular (2003) y } \\
\text { Norma Territorial Transitoria (2014). }\end{array}$ & $\begin{array}{l}\text { Suelo rústico protegido de especial } \\
\text { interés. }\end{array}$ & \\
\hline
\end{tabular}

Área de interés paisajístico.

Resto del suelo rústico.

Fuente: elaboración propia a partir de los documentos citados.

La afección territorial de las normas patrimoniales y de planificación y sus catalogaciones en el paisaje ganadero de Punta Nati reflejan la inoperancia de la normativa vigente para el reconocimiento patrimonial de los paisajes culturales de dominante agraria.

\section{Proyectos de energías renovables previstos en el paraje de Punta Nati y sus valoraciones sociales}

La cuestión energética y el deterioro atmosférico asociado al uso de energías fósiles es uno de los problemas ambientales actuales más acuciantes. En una isla donde la autosuficiencia energética adquiere una especial significación, que además se integra en la Red de Reservas de la Biosfera de la Unesco, la apuesta por las energías limpias es una prioridad. En ese contexto, y con el soporte de la normativa territorial descrita, varias empresas locales inician en 2008 la tramitación de proyectos de energías renovables en Punta Nati, con una capacidad de 85,25 MW. Dos de ellos eran proyectos de energía eólica (Son Angladó y S'Era Vella); el tercero (Son Salomó) preveía la ampliación de 14 a 173 hectáreas de una planta fotovoltaica ya existente, pasando de 3,2 a 49,8 MW y que contaría con más de 250.000 placas solares tras la ampliación (tabla 4). Habida cuenta de los valores naturales, culturales y paisajísticos de este paraje, ello provocó un intenso debate, especialmente en la vecina Ciutadella. Las afecciones paisajísticas y patrimoniales varían en cada caso:

- Los proyectos de energía eólica tienen un impacto espacial puntual y localizado, aunque dada la verticalidad de los aerogeneradores la afección visual es muy potente. Las principales críticas que han recibido tienen que ver, no con su impacto paisajístico, sino con las interferencias en el hábitat de dos especies de aves protegidas: el milano real y el alimoche. Ello derivó en el informe ambiental desfavorable emitido por la Comisión de Medio 
Figura 4. Parques fotovoltaicos en Son Salomó

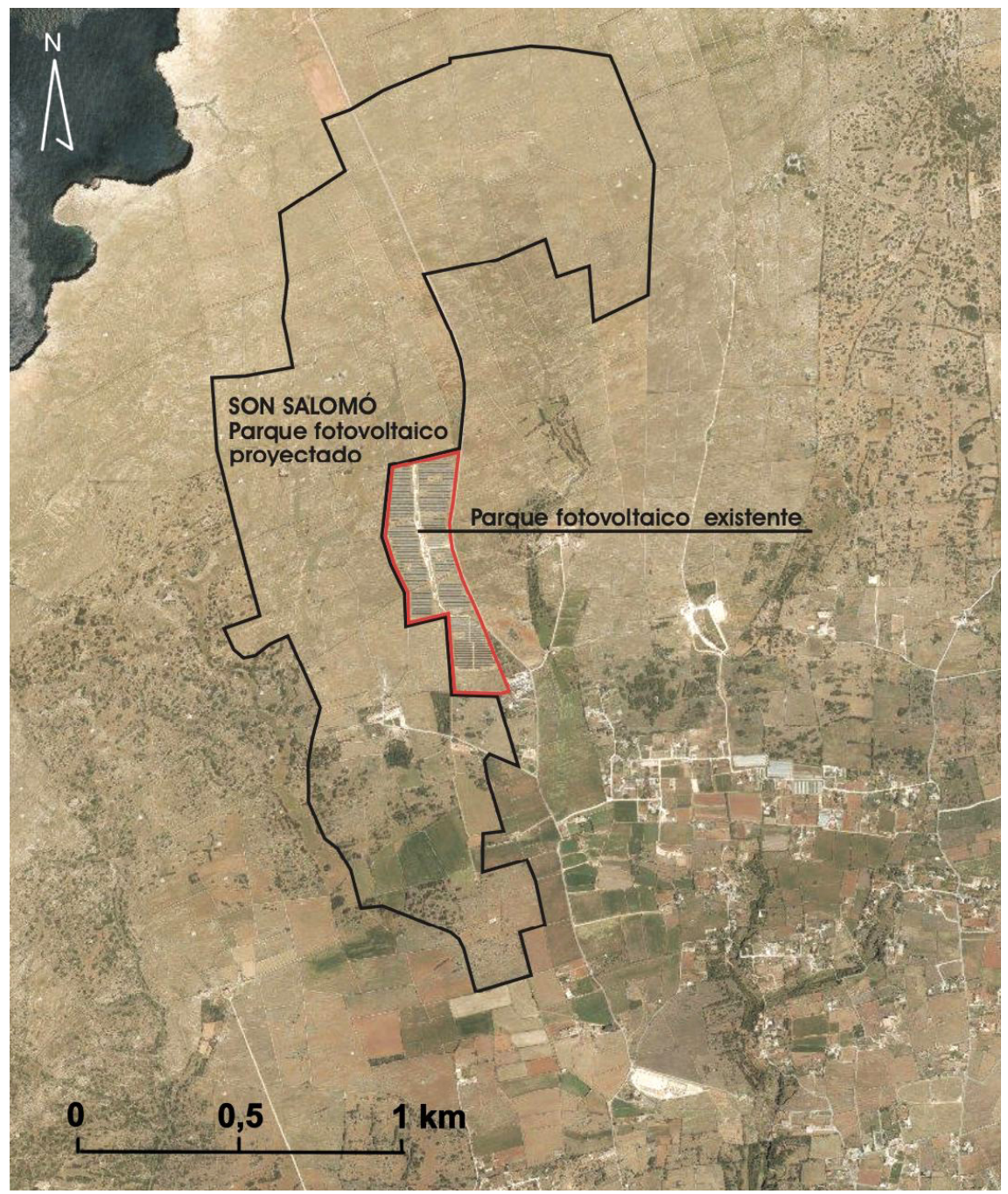

Fuente: Societat Arqueològica Martí i Bella.

Ambiente de las Islas Baleares (Boletín Oficial de las Islas Baleares, n. ${ }^{\circ}$ 67, de 28 de mayo de 2016), lo que implicó su paralización.

- Diferente es la situación de la planta fotovoltaica de Son Salomó; allí la afección es horizontal y tiene un doble calado: a) paisajístico, a su vez relacionado con dos factores: su amplia extensión y el enmascaramiento del parcelario por la superposición de una gran mancha de paneles solares (figura 4), y b) patrimonial, por la presencia de vestigios arqueológicos y la 
riqueza de la cultura ganadera. Es precisamente sobre este proyecto sobre el que gravita la polémica. De desarrollarse, Son Salomó se convertiría en una de las mayores instalaciones españolas de este tipo cuando, en términos comparativos, la extensión de Menorca es de $696,7 \mathrm{~km}^{2}$ (el 0,1\% de la superficie española) y el paraje de Punta Nati solo ocupa $29,5 \mathrm{~km}^{2}$.

\subsection{Agentes implicados: Percepciones, valores y propuestas}

Entre los agentes más activos en el debate cabe señalar:

- La Societat Arquelògica Martí i Bella. Propone la desmembración de la planta fotovoltaica de Son Salomó y su reubicación en otras partes de la isla. Destaca, entre sus iniciativas, la propuesta, sin éxito, de declarar el paisaje ganadero de Punta Nati como Bien de Interés Cultural en calidad de Lugar de Interés Etnológico (la Ley de Patrimonio Histórico de las Islas Baleares no incluye la figura de paisaje cultural). En diciembre de 2015 interpuso una reclamación al Comité Nacional Español de Icomos, de la que deriva un informe favorable a sus intereses presentado en febrero de 2016.

- El Grup Balear d'Ornitologia i Defensa de la Naturalesa (GOB). Junto con las empresas licitadoras es el principal valedor del proyecto de Son Salomó. Posee una gran influencia institucional y social en Menorca. No se muestra insensible a los valores patrimoniales y paisajísticos de Punta Nati, pero antepone los beneficios ambientales derivados de la ampliación de la planta fotovoltaica a los valores de los recursos patrimoniales y paisajísticos, sobre todo por el compromiso de la isla como reserva de la biosfera.

- El Consell Insular de Menorca es el tercer protagonista en el litigio y actúa en cierta medida como mediador. Sin renunciar a la planta fotovoltaica, ha orientado los esfuerzos en varias direcciones: la reducción de la extensión del parque (de 173 hectáreas a 135); la eliminación de los molinos aerogeneradores; la incorporación de medidas para mitigar el impacto paisajístico; la garantía de conservación y rehabilitación de los bienes de interés cultural del área afectada, y la garantía de reversibilidad de la instalación cuando el parque deje de ser útil.

\subsection{Estado actual de la polémica}

La situación actual se puede sintetizar como sigue:

- Los proyectos de energía eólica previstos en Punta Nati se han paralizado, aunque no por sus impactos paisajísticos, sino porque comprometen el hábitat del alimoche. El impacto ambiental y paisajístico de la planta fotovoltaica de Son Salomó se ha reducido, pero sigue siendo considerable por su extensión desproporcionada respecto a la superficie y a las características del paraje. La mayor fuerza institucional y mediática del Grup Balear d'Ornitologia i Defensa de la Naturalesa (GOB) respecto a la Societat 
Arquelògica Martí i Bella ha tenido un papel destacado en la estimación del proyecto, aunque también influyeron las elevadas indemnizaciones que habría que pagar a las empresas licitadoras si se revirtieran las licencias otorgadas en 2008.

- El hecho más destacable de la polémica es que, en cierta medida, se está consiguiendo revertir la desconsideración patrimonial de los paisajes agrícolas y ganaderos. La Modificación del Plan Territorial Insular, en fase de avance, aprobada por el Consell en febrero de 2018, expresa gran interés y preocupación por los paisajes agrarios en general y por los ganaderos de Punta Nati en particular. Plantea, a tal fin, la ordenación del suelo rústico a través de una nueva zonificación con dos categorías: $a$ ) el suelo rústico protegido, y b) el suelo rústico común. El primero, amén de otras áreas, incluiría las Áreas Naturales de Interés Territorial y las Áreas de Interés Paisajístico de la Ley 1/1991, de Espacios Naturales y Régimen Urbanístico de las Áreas de Especial Protección de las Islas Baleares. Ello supone de facto un mayor reconocimiento patrimonial de las segundas. Respecto al Área de Interés Paisajístico de Punta Nati, se indica de forma expresa: «Las AIP [Áreas de Interés Paisajístico] incluyen morfologías territoriales de especial valor cultural, ligadas a la práctica de la piedra en seco, en particular en el norte del término municipal de Ciutadella» (ibidem: 130). En noviembre de 2018 (con posterioridad a la culminación de este estudio) los muros de piedra seca fueron incluidos en la Lista Representativa del Patrimonio Inmaterial de la Humanidad de la Unesco.

- El Avance de la Modificación del Plan Territorial Insular de 2018 plantea la rezonificación y ampliación de la Reserva de la Biosfera de Menorca. En los llanos ganaderos de Punta Nati ello implicaría el cambio desde la actual categoría de zona de transición de la reserva a la de amortiguamiento (buffer zone). Con respecto a la candidatura Menorca Talayótica a la Lista del Patrimonio Mundial, el Avance plantea una nueva tipología de protección de los entornos de los talayots. Estos contarán a partir de ahora con un perímetro de protección y gestión paisajística que implica la superación del carácter territorial puntual de los bienes de interés cultural.

\section{Conclusiones}

El análisis comparado de las bases epistemológicas y normativas de los conceptos de patrimonio, paisaje y medio ambiente ha permitido confirmar que se trata de nociones complejas, dinámicas y concurrentes. Esto último es debido, en parte, aunque no solo, al acercamiento y a la asimilación (al menos en teoría) entre el patrimonio natural y cultural y su confluencia en el paisaje. También ha pesado la importancia de los significados perceptivos y valorativos en su consideración actual: el paisaje se entiende como percepción; el patrimonio, como asignación de valores, y el medio ambiente, como un constructo social. En este marco los estudios sobre percepciones sociales cobran un protagonismo muy relevante. 
De los tres conceptos manejados (patrimonio, paisaje y medio ambiente), es el ambiental el que cuenta con un calado social e institucional más potente y con el que se equiparan los restantes. Un medio ambiente saneado es indicativo de un paisaje equilibrado y armónico y, también, resulta tópica la identificación de este último con bienes patrimoniales de especial valor. En caso de conflictos la polémica se dirime en clave de criterios estrictamente medioambientales. Ello es particularmente evidente cuando el debate gira en torno a la cuestión energética. La asimilación entre energías limpias y calidad ambiental pesa más en los idearios sociales e institucionales que los valores patrimoniales y paisajísticos de los territorios.

La noción de medio ambiente es, por otra parte, ambivalente. Se utiliza indistintamente para aludir a bienes naturales de carácter ubicuo (el aire, el agua o el suelo) y a bienes específicos anclados en los territorios (elementos y espacios naturales únicos). De esto último deviene otra confusión y asimilación entre recursos y bienes patrimoniales. Este trabajo postula que:

1) Los significados de las nociones de paisaje, patrimonio y medio ambiente están entrelazados, pero no por ello resultan sinónimos. A menudo conviene deslindarlos, particularmente en el caso de paisajes culturales de dominante agraria, cuya valoración patrimonial, paisajística y ambiental es muy reciente.

2) También se aboga por la diferenciación entre recursos y bienes patrimoniales, especialmente en relación con los naturales. Los primeros tienen un carácter universal y la responsabilidad de su gestión no debería hacerse recaer específicamente en territorios concretos, por más que estos desempeñen un papel clave en la gestión sostenible de esos recursos. Los bienes patrimoniales (naturales, culturales y paisajísticos) son, en cambio, recursos específicos y precisan de una gestión territorializada. La distinción entre el concepto de recurso - de raigambre económica - y el de bien patrimonial - para el que el retorno económico es importante pero lo fundamental es la preservación - es una tarea imprescindible.

El análisis del paraje de Punta Nati atendiendo a la polémica suscitada por la implantación de plantas de energía renovable es ilustrativo de las confusiones antedichas. Desde un punto de vista paisajístico, Punta Nati es un paraje de significantes y significados contradictorios. Amplias panorámicas y espectaculares oteros marítimos lo revalorizan como paisaje, a la par que acrecientan su vulnerabilidad visual. La historia (talayótica y ganadera) lo dota de un patrimonio cultural singular y excepcional, aunque no siempre reconocido o, cuando lo es, de forma muy diferencial en razón de las instituciones o de los grupos sociales que lo valoran. Su carácter árido, de escasa vegetación y esquilmado por el sobrepastoreo lo aparta de los cánones comunes del patrimonio ambiental, que asimilan lo natural con lo verde y arbóreo. La titularidad privada de la red caminera que lo recorre, a pesar de las servidumbres ancestrales de paso, contribuye a la menor visibilidad de este paisaje. 
Las contradicciones en los significantes paisajísticos de Punta Nati se hacen patentes en los desacuerdos sobre las afecciones de los proyectos de energías renovables programados en su territorio. El más impactante de ellos, la ampliación de la planta fotovoltaica de Son Salomó, se superpone y enmascara paisajes ganaderos ancestrales dotados de elementos constructivos de gran valor y de un patrimonio genético de razas en peligro de extinción. Es precisamente este el proyecto que sigue adelante, aunque mitigándose sus impactos ${ }^{1}$. Se ha conseguido detener los proyectos de aerogeneradores, aunque no por sus afecciones paisajísticas (más puntuales), sino porque comprometen el hábitat de aves protegidas. La primacía del discurso ambiental sobre el paisajístico y la escasa valoración de los paisajes ganaderos resultan con ello evidentes.

Este trabajo también ilustra la inoperancia de los instrumentos normativos vigentes para el reconocimiento y la preservación de los valores de los paisajes patrimoniales de dominante agraria. La integración de Punta Nati en la Reserva de la Biosfera de Menorca le confiere, como al resto de la isla, un reconocimiento internacional del más alto rango. Otro tanto cabe señalar respecto a la candidatura Menorca Talayótica a la Lista del Patrimonio Mundial, en proceso de revisión como paisaje cultural. Se trata, no obstante, de reconocimientos que, o bien excluyen a Punta Nati (caso de la candidatura Menorca Talayótica), o bien entienden poco y protegen menos su paisaje ganadero integrado en la zona de transición de la reserva de la biosfera. La importancia concedida a los habitantes y a sus actividades tradicionales por parte del programa $\mathrm{MaB}$ parece quedar solo sobre el papel.

Las normas relacionadas con la preservación de los bienes patrimoniales de Menorca reproducen y son causa de todo lo apuntado. La Ley de Espacios Naturales y Régimen Urbanístico de las Áreas de Especial Protección de las Islas Baleares (1/1991) no proporciona criterio de catalogación alguno para la protección del paisaje ganadero de Punta Nati. La Ley del Patrimonio Histórico balear cataloga en el paraje hasta ochenta bienes de interés cultural, pero todos ellos son yacimientos arqueológicos con una afección espacial puntual. $\mathrm{Al}$ mismo tiempo, la propuesta de declaración de los paisajes y de la cultura ganadera como bien de interés etnográfico impulsada por la Societat Arqueològica Martí i Bella no consiguió prosperar.

Por la extensión e imprecisión de su proyección y delimitación espacial, el paisaje se entiende mejor desde la ordenación del territorio, pero el planeamiento espacial reproduce los preceptos de las normas patrimoniales (que son de carácter vinculante). Se entra así en una suerte de círculo vicioso en la gestión territorial y patrimonial del paisaje, de lo que Punta Nati es un buen

1. El 25 de febrero de 2020, cuando este artículo, además de aceptado, ya estaba corregido, se realizó un acuerdo entre el Consell Insular de Menorca, la promotora del parque fotovoltaico, la propiedad de Son Salomó y la asociación Martí i Bella. Por este acuerdo, la superficie del parque se reduce de las 173 ha iniciales a 68, y el Consell se compromete a la restauración de los bienes etnológicos, a habilitar un recorrido para visitar la zona, a construir una plataforma para la observación del paisaje cultural y a incoar una declaración de bien de interés cultural de 950 ha, que recoge la mayor parte de este paisaje cultural. 
ejemplo. El Plan Territorial Insular cataloga la franja litoral de Punta Nati como suelo rústico protegido de especial interés, en consonancia con sus reconocimientos como Lugar de Interés Comunitario (LIC), Zona de Especial Protección para las Aves (ZEPA), espacio de la Red Natura 2000 y Área Natural de Interés Territorial, de la Ley de Espacios Naturales y Régimen Urbanístico de las Áreas de Especial Protección de las Islas Baleares. En cambio, los llanos ganaderos, aunque también merecedores de catalogación por el Plan Territorial Insular de 2003, lo fueron en una categoría más permisiva respecto al cambio de uso (Área de Interés Paisajistico).

Las asociaciones implicadas en la polémica reproducen en sus planteamientos la dicotomía tradicional del mundo del patrimonio. La mayor fuerza institucional y mediática del Grup Balear d'Ornitologia i Defensa de la Naturalesa (GOB) respecto a la Societat Arquelògica Martí i Bella ha tenido un peso importante en la polémica. Se refuerza con ello la primacía del discurso ambiental sobre el cultural. La Administración regional mediadora en el conflicto a través de la política de ordenación del territorio ha logrado la reducción superficial del proyecto y eliminar los elementos más impactantes: los aerogeneradores, pero no así las contradicciones de fondo. La extensión — 135 hectáreas - sigue siendo una superficie considerable y fuera de escala para las características de Punta Nati. La mitigación del impacto paisajístico acrecentando la altura de los muros de piedra seca ocultará los paneles solares, pero también los paisajes; la rehabilitación de los bienes de interés cultural ubicados dentro del área no evitará la pérdida de autenticidad e integridad del conjunto del paraje, y la garantía de reversibilidad de la instalación al cabo de treinta años tampoco está asegurada.

El ejemplo de Punta Nati es significativo y expresivo de las contradicciones derivadas de la asimilación entre medio ambiente, patrimonio y paisaje, así como de la confusión entre recursos genéricos y específicos. También evidencia las potencialidades del paisaje para dirimir problemas patrimoniales y territoriales complejos. Las continuas alusiones a los paisajes ganaderos de Punta Nati por el avance de la Modificación del Plan Territorial Insular de 2018 así lo atestiguan, a la par que se entrevé una lectura en positivo de la polémica: la reversión a raíz de ella, y sin vuelta atrás, de la desconsideración tradicional hacia los paisajes patrimoniales de dominante agraria.

\section{Referencias bibliográficas}

Ainz Ibarrondo, M.J. y González Amuchástegui, M.J. (2016). «Impacto del desarrollo urbanístico reciente en el paisaje del caserío vasco: Una propuesta metodológica en la Reserva de la Biosfera de Urdabai». Boletín de la Asociación de Geógrafos Españoles, 70, 305-327.

Andrés, C. de e Iranzo, E. (2011). «Desarrollo de las energías renovables y cambios paisajísticos: Propuesta de tipología y localización geográfica de los paisajes energéticos de España». En: Gozálvez Pérez, V. y Marco Molina, J.A. (eds.). Energía y territorio: Dinámicas y procesos. Alicante: Asociación de Geógrafos Españoles, Colegio de Geógrafos de España y Universidad de Alicante, 97-107. 
Batisse, M. (1982). «The Biosphere Reserve: A tool for environmental conservation and management». Environmental Conservation, 9 (2), 101-111.

Briffaud, S.; Heaulmé, E.; André-Lamat, V.; Davasse, B. y Sacareau, I. (2015). "The nature of resources: Conflicts of landscape in the Pyrenees during the rise of hydroelectric power». En: Frolova, M.; Prados, M.J. y Nadaï, A. (eds.). Renewable Energies and European Landscapes: Lessons from Southern European Cases. Dordrecht: Springer Netherlands, 135-153.

Bruntland, G.H. (1987). Informe de la Comisión Mundial sobre el medio ambiente y el desarrollo: Nuestro futuro común. Nueva York: Naciones Unidas.

Castillo Ruiz, J. y Martínez Yáñez, C. (2014). «El patrimonio agrario: Definición, caracterización y representatividad en el ámbito de la Unesco». Boletín de la Asociación de Geógrafos Españoles, 66, 105-124.

Conti, A. y Cravero Igarza, S. (2010). «Patrimonio, comunidad local y turismo: La necesidad de planificación para el desarrollo sostenible». Notas en Turismo y Economía, 1, 8-31. Recuperado de <http://sedici.unlp.edu.ar/handle/10915/15769>.

Cowell, R. (2010). «Wind power, landscape and strategic, spatial planning: The construction of acceptable locations in Wales». Land Use Policy, 27 (2), 222-232.

Delgado Viñas, C. (2008). "Urbanización sin fronteras”: El acoso urbanístico a los espacios naturales protegidos». Boletín de la Asociación de Geógrafos Españoles, 47, 271-319.

Devine-Wright, P. y Devine-Wright, H. (2006). «Social representations of intermittency and the shaping of public support for wind energy in the UK». International Journal of Global Energy Issues, 25 (3/4), 243-256.

Díaz Cuevas, M.P.; Fernández Tabales, A. y Pita López, M.F. (2016). «Energía eólica y paisaje: Identificación y cuantificación de paisajes afectados por instalaciones eólicas en Andalucía». Boletín de la Asociación de Geógrafos Españoles, 17, 397-430.

Folch, R. y Bru, J. (2017). Ambiente, territorio y paisaje: Valores y valoraciones. Barcelona: Barcino; Madrid: Aquae Fundación.

Frolova, M. (2010b). «Los paisajes de la energía eólica: Su percepción social y gestión en España». Nimbus, 25-26, 93-110.

Frolova, M.; Espejo, C.; Baraja, E. y Prados, M.J. (2014). «Paisajes emergentes de las energías renovables en España». Boletín de la Asociación de Geógrafos Españoles, $66,223-252$.

González, A.; Hernández, J.A. y Parreño, J.M. (2016). «Nuevos usos turísticos en la reserva de la biosfera de la Isla de la Palma (Canarias)». Boletín de la Asociación de Geógrafos Españoles, 70, 239-257.

Hernández Hernández, M. (2009). «El paisaje como seña de identidad territorial: Valorización social y factor de desarrollo, ¿utopía o realidad?». Boletín de la Asociación de Geógrafos Españoles, 49, 169-183.

Herrero Luque, D. y Baraja Rodríguez, E. (2017). «Estudio geográfico de la energía: Una aproximación histórica al estado de la cuestión». Boletín de la Asociación de Geógrafos Españoles, 74, 169-183.

MARQUÉs, D. (2015). «Los cuatro parques en tramitación suman la energía que la isla necesita en invierno». Menorca. Recuperado de <http://menorca.info/menorca/ local/2015/499465/cuatro-parques- tramitacion-suman-energia-isla-necesitainvierno.html>.

MÉndeZ, R. (2002). «Innovación y desarrollo territorial: Algunos debates teóricos recientes». Eure, 28 (84), 63-83. 
Menorca, Reserva de Biosfera. La isla de Menorca. Recuperado de <http://www. biosferamenorca.org/Contingut.aspx?idpub=2764>.

Mulero Mendigorri, A. (2017). «Territorio y áreas protegidas en España y Portugal: Dos modelos de intervención en una geografía compartida». Boletín de la Asociación de Geógrafos Españoles, 74, 205-227.

Nadaï, A.; Krauss, W.; Alfonso, A.I.; Dracklé, D.; Hinkelbein, O.; Labussiére, O. y Mendes, C. (2010). «El paisaje y la transición energética: Comparando el surgimiento de paisajes de energía eólica en Francia, Alemania y Portugal». Nimbus, 25-26, 155-174.

Prats Canals, L. (2005). "Concepto y gestión del patrimonio local». Cuadernos de Antropología Social, 21, 17-35.

Silva PÉrez, R. (2008). "Hacia una valoración patrimonial de la agricultura». Scripta Nova. Revista Electrónica de Geografía y Ciencias Sociales, vol. XII (275), 21 de julio de 2012. Recuperado de <http://www.ub.edu/geocrit/sn/sn-275.htm>.

Silva Pérez, R. y Fernández Salinas, V. (2017). «El nuevo paradigma del patrimonio y su consideración con los paisajes: conceptos, métodos y prospectivas». Documents d'Anàlisi Geogràfica, 63 (1), 129-151. <https://doi.org/10.5565/rev/dag.344>

Silva Pérez, R.; Fernández Salinas, V. y Mata Olmo, R. (2018). "Concepto, ámbito y significado de los paisajes patrimoniales». En: Molinero, F.; Tort, J.; Mata, R.; Silva, R.; García, L.; Porcal, M.C. y Ruiz, E. (coords.). Paisajes patrimoniales de España. Madrid: Ministerio de Agricultura, Pesca y Alimentación, 17-38.

West, J.; Bailey, I. y Winter, M. (2010). «Renewable energy policy and public perceptions of renewable energy: A cultural theory approach». Energy Policy, 38 (10), 5739-5748.

\section{Referencias documentales}

Consejo de Europa (2000). Convenio Europeo del Paisaje. Recuperado de <https://www.mapa.gob.es/es/desarrollo-rural/planes-y-estrategias/desarrolloterritorial/090471228005d489_tcm30-421583.pdf>.

Consejo Internacional de Monumentos y Sitios. Icomos (2016). Informe sobre el Paraje de Punta Nati (Menorca, Islas Baleares). Recuperado de <http://studylib. es/doc/7866915/informe-sobre-el-paraje-de-punta-nati>.

Consell Insular de Menorca (2003). Plan territorial insular de Menorca. Recuperado de <https:/www.iberley.es/legislacion/aprobacion-definitiva-plan-territorialinsular-menorca-170901>.

- (2006). Modificació del Pla Territorial de Menorca. Recuperado de <http://www. cime.es/WebEditor/Pagines/file/DOCPTI/modificacions_PTI_ple_26062006. pdf $>$.

- (2015). Norma Territorial Transitoria. Recuperado de <http://www.cime.es/publicacions/verpub.aspx?IDIOMA=2\&Id=4396>.

(2018). Revisión del Plan Territorial Insular de Menorca: Avance. Recuperado de <http://www.pimemenorca.org/documento/699/pti-menorca>.

Societat Arqueològica Martí i Bella (2013). Sol.licitud de declaració de bé d'interès cultural amb categoria de lloc d'interès etnològic de la zona nord-oest de Menorca coneguda com a Punta Nati o Tramuntana. 
Unesco (1971). Man and the Biosphere Programme. Recuperado de <http://www. unesco.org/new/en/natural-sciences/environment/ecological-sciences/man-andbiosphere-programme/s.

- (1972). Convención para la Protección del Patrimonio Mundial, Cultural y Natural. Recuperado de <https://whc.unesco.org/archive/convention-es.pdf>.

- (2015). Programa Internacional de Geociencias y Geoparques. Recuperado de <http:// www.globalgeopark.org>.

Unión Europea (2009). Directiva 79/09/CEE del Parlamento Europeo y del Consejo relativa a la conservación de las aves silvestres. (Reemplaza a la directiva 2009/147/CE.) Recuperado de <https://eur-lex.europa.eu/legal-content/es/ TXT/?uri=CELEX\%3A32009L0147>. 